Research Paper

\title{
IL28B SNP rs 12979860 is the Critical Predictor for Sustained Viral Response in Chinese Children Aged 1 to 6 Years with Chronic Hepatitis C
}

Yan-Wei Zhong ${ }^{1 * \varpi}$, Hong-Fei Zhang ${ }^{1 *}$, Yan-Min Shi ${ }^{*}$, Yong-Li Li ${ }^{1}$, Fang Chu ${ }^{1}$, Zhi-Qiang Xu' Da-Wei Chen ${ }^{1}$, Yu Gan ${ }^{1}$, Fu-Chuan Wang ${ }^{1}$, Mei-Lei Gu${ }^{1}$, Yi Dong ${ }^{1}$, Shi-Shu Zhu ${ }^{1}$, Ce Shi ${ }^{1}$, Hua-Hao Fan"1, Xiu-Chang Zhang ${ }^{2 凶}$, Min Zhang ${ }^{1 凶}$

1. Institute of Infectious Diseases, pediatric liver disease therapy and research center, Xisihuan mid-road No.100, Beijing 302 Hospital, Beijing, China.

2. HeBei North University, Changqing road No.36, Zhangiiakou, China.

*These authors contributed equally to this work.

$\triangle$ Corresponding authors: Prof. Yanwei Zhong, Institute of Infectious Diseases, pediatric liver disease therapy and research center, Xisihuan mid-road No.100, Beijing 302 Hospital, Beijing, China. Email: zxc@hebeinu.edu.cn. Telephone: (8610)66933465(O), (8610)66933465(Fax); Prof. Xiuchang Zhang, HeBei North University, Changqing road No.36, Zhangiiakou, China. Email: zhangxiuchang302@163.com; Dr. Min Zhang, Institute of Infectious Diseases, pediatric liver disease therapy and research center, Xisihuan mid-road No.100, Beijing 302 Hospital, Beijing, China. Email: zhangmin302302@163.com

(1) Ivyspring International Publisher. Reproduction is permitted for personal, noncommercial use, provided that the article is in whole, unmodified, and properly cited. See http://ivyspring.com/terms for terms and conditions.

Received: 2016.05.18; Accepted: 2016.08.26; Published: 2016.10.25

\begin{abstract}
Clinical data on children with chronic hepatitis $\mathrm{C}(\mathrm{CHC})$ remain extremely limited. This study investigated sustained virologic response (SVR) to alfa-interferon $2 \mathrm{~b}$ plus RBV treatment in children aged 1-6 years with unsafe injection-acquired $\mathrm{CHC}$. 154 children with $\mathrm{CHC}$ aged 1 to 6 years were enrolled, 101 of them were male $(65.6 \%)$ and 53 were female $(34.4 \%)$, and they were treated with alfa-interferon at a dose of $1-5 \mathrm{MIU} / \mathrm{m}^{2} 3$ times weekly plus oral RBV $(15 \mathrm{mg} / \mathrm{kg} /$ day $)$ for 48 weeks. 57(39.3 \%) of them were genotype 1b, 73(50.3\%) were genotypes $2 a, 15(10.3 \%)$ were undecided type. SVR was achieved in 53 of $57(93.0 \%)$ patients with genotype $1 \mathrm{~b}$, in 72 (98.6\%) of 73 with genotype $2 a, 15(100.0 \%)$ of 15 with undecided type. There was no significant statistical difference in SVR between male and female ( $98.0 \%$ vs $94.3 \%, p=0.340)$, genotype $2 a$ and those with genotype $1 \mathrm{~b}(98.6 \%$ vs $93.0 \%, p=0.160)$, ALT>40U/L group and ALT $\leq 40 \mathrm{U} / \mathrm{L}$ group $(96.7 \%$ vs $96.8 \%, p=1.000), A S T>40 \mathrm{U} / \mathrm{L}$ group and $\mathrm{AST} \leq 40 \mathrm{U} / \mathrm{L}$ group $(95.9 \%$ vs $98.2 \%$, $p=0.654)$ as well as lower baseline viral load group $\left(<6 \times 10^{5} \mathrm{IU} / \mathrm{ml}\right)$ and higher baseline viral load group $\left(\geq 6 \times 10^{5} \mathrm{IU} / \mathrm{ml}\right)(97.3 \%$ vs $95.3 \%, p=0.916)$. Leucopenia, neutropenia, hemoglobin concentration decrease, fever, platelet count decrease and rash were $8.4 \%, 69.5 \%, 24.0 \%, 50.6 \%$, $1.9 \%$ and $4.5 \%$, respectively. And only $12(7.8 \%)$ individuals developed thyroid autoantibodies. The SVR was higher in patients with IL-28B genotype $C / C$ than $C / T$ ( $99.0 \%$ vs $80 \%, p=0.002)$. Compared with HCV viral genotype, ALT level and baseline viral load, IL-28B rs 12979860 is more suitable for predicting antiviral efficacy in children with $\mathrm{CHC}$. It is inappropriate to take the increase of ALT level as an essential indicator for antiviral treatment in children aged 1-6 years.
\end{abstract}

Key words: chronic hepatitis C, IL-28B rs12979860

\section{Introduction}

Combination therapy of interferon alfa and RBV has become standard treatment in adults with chronic hepatitis C (CHC) [1-6]. Although several studies have been performed on the treatment of $\mathrm{CHC}$ with interferon-alfa and RBV between 3 to 16 years of age, most of the patients were infected via vertical transmission, limited data are available regarding the use of interferon-alfa combined with RBV in children aged 1 to 6 years, especially those were infected by unsafe injection route. Christensson et al. [7] and 
Lackner et al. [8] reported encouraging results in a small number of children and adolescents with malignant disease in remission and chronic hepatitis C, SVR were $64 \%$ and 50\%, respectively. However, many of them were infected with genotype 3 hepatitis $C$ virus. The lack of safe and highly efficient therapies during childhood with $\mathrm{CHC}$ in China resulted in increasing adulthood burden of advanced hepatitis $\mathrm{C}$ disease [9]. The aim of the study was to investigate SVR to the alfa-interferon $2 \mathrm{~b}$ plus RBV treatment in children aged 1-6 years with unsafe injection-acquired $\mathrm{CHC}$ in China.

\section{Materials and Methods}

\section{Study population}

154 naive patients with $\mathrm{CHC}$ treatment were enrolled in the study. Mean age at diagnosis was $2.92 \pm 1.37$ years, range from 1 to 6 years. The children received recombinant alfainterferon- $2 b$ at the dosage of $1-5 \mathrm{MIU} / \mathrm{m}^{2}$ of 3 times weekly in combination with oral ribavirin $(15 \mathrm{mg} / \mathrm{kg} / \mathrm{d})$ for 48 weeks. The efficacy was evaluated by the SVR and side effects.

\section{Diagnosis}

$\mathrm{CHC}$ infection was diagnosed on the basis of anti-HCV antibodies and quantitative serum $\mathrm{HCV}$ RNA determination. Virologic response is defined as HCV-RNA level cannot be detected and ALT return to the normal level [10]. The level of serum HCV RNA was quantified by the COBAS Taqman HCV Test (Roche Molecular Systems), and the threshold was 15 $\mathrm{IU} / \mathrm{mL}$. The human genome DNA was extracted from the blood samples using a QIAamp DNA Blood Mini Kit (Qiagen, Germany), and the primer used for amplying the IL-28B was: 5'-TCGCCAGGGCCC CTAACCTC-3' (forward primer) and 5'-CCCAGC AGGCGCCTCTCCTA-3' (reverse primer). The sequencing results from Sangon Biotech (Shanghai) were analyzed by Vector NTI for genotyping. The baseline viral load was classified as low baseline viral load $\left(<6 \times 10^{5} \mathrm{IU} / \mathrm{mL}\right)$ and high baseline viral load $\left(\geq 6 \times 10^{5} \mathrm{IU} / \mathrm{mL}\right)$ as described in previous study [11, 12]. And the endpoint of therapy is the SVR, defined by undetectable HCV RNA 24 weeks after the end of therapy, as assessed by a sensitive molecular method with a lower limit of detection < $15 \mathrm{IU} / \mathrm{ml}$ [13]. The lack of response to therapy was defined as HCV viral load decline less than 2 logs at week 12 during therapy or detectable HCV RNA in serum at any other time during the 48-week therapy. Relapse was defined as undetectable HCV RNA in serum at the end of therapy, followed by detectable HCV RNA after the completion of therapy. Breakthrough was defined as reappearance of HCV RNA at any time during treatment after a negative result or increase of
$1 \log \mathrm{IU} / \mathrm{ml}$ from nadir. The early virological response (EVR) is defined as an HCV RNA, which is undetectable at week 12[13]. The criterion for inclusion for this study was confirmed as chronic hepatitis $\mathrm{C}$ by detection of HCV RNA. The patients had not severe chronic hepatitis or cirrhosis, and pretreatment antibodies against liver kidney membrane autoantibodies were negative, hyroid function was normal. The exclusion criteria included hepatitis B or human immunodeficiency virus (HIV) coinfection, coexistent autoimmune liver diseases, hemochromatosis or other coexistent chronic liver diseases (Wilson's disease), metabolic liver disorders, prior immune suppressive therapy and severe neurologic impairment.

\section{Monitoring}

Blood and serum analyses as well as a physical examination were performed every 2 weeks for the first 4 weeks, then every 3 months until the end of treatment, and thereafter at the third and sixth months of post therapy follow-up evaluation. Monitoring of treatment side effects was performed by recording patient parents' dictation at each visit.

\section{Statistical analysis}

Statistical analysis was carried out using the SPSS 19.0 statistical software package, the continuous variables were expressed as the means \pm SD (range) and compared using Student's unpaired $t$ test (Table 4). Categorical variables were reported as the number of cases (percentage), frequencies were compared using the $x^{2}$ test or Fisher's exact test (Table 2 and Table 4). Several factors implicated as possibly predictive of SVR rate in previous adult studies were entered in logistic regression analysis (Table 4) to evaluate their impact on the response to HCV therapy in our pediatric population. $\mathrm{P}$ values less than 0.05 were regarded as statistically significant.

\section{Ethics statement}

The study protocol was approved by the Beijing 302 Hospital Research Ethnics Committee, and written informed consents for therapy and study were obtained from each patient's parents.

\section{Results}

\section{Demographic Data}

154 patients with $\mathrm{CHC}$ aged 1 to 6 years were enrolled, and patients' baseline characteristics are showed in Table 1 . The mean age \pm standard deviation (SD) was $2.92 \pm 1.37$ years. 101 of them $(65.6 \%)$ were male and 53(34.4\%) were female. Histological examination showed mild or moderate chronic inflammatory activity and low degree of fibrosis in all 
154 patients. The HCV genotype distribution was 57 (39.3\%) patients with genotype $1 \mathrm{~b} ; 73(50.3 \%)$ with genotype $2 \mathrm{a}, 15$ with undecided type $(10.3 \%)$. The mean \pm SD of the HCV RNA baseline viral load was $4.76 \pm 1.41\left(\log _{10} \mathrm{IU} / \mathrm{mL}\right)$. ALT level in $59.1 \%$ was more than $40 \mathrm{U} / \mathrm{L}$ and in $40.9 \%$ was less than $40 \mathrm{U} / \mathrm{L}$. Among those patients, IL-28B rs12979860 was detected in 123 patients. $\mathrm{C} / \mathrm{C}$ and $\mathrm{C} / \mathrm{T}$ genotypes accounted for $83.7 \%$ (103/123) and 16.3\% (20/123), respectively. Rather than conventional examination, IL-28B genotype detection is an optional detection, some patients refused to perform IL-28B genotype detection due to extra expense, that is the reason why there was $20 \%$ missing genotype information. As a retrospective study, all data were collected after the treatment and then analyzed.

TABLE 1. Baseline characteristics of 154 children with $\mathrm{CHC}$ before treatment

\begin{tabular}{llll}
\hline Factor & number & proportions & Mean \pm SD \\
\hline $\begin{array}{l}\text { Total Number } \\
\text { Age(years) }\end{array}$ & & & \\
$\begin{array}{l}\text { Median(range) } \\
\text { Age range(years) }\end{array}$ & & & $2.92 \pm 1.37$ \\
Sex & $1-6$ & & \\
Male & & & \\
Female & 101 & $65.6 \%$ & \\
HCV genotype & 53 & $34.4 \%$ & \\
1b & & & \\
$2 a$ & 57 & $39.3 \%$ & \\
Undecided type & 73 & $50.3 \%$ & \\
IL28B genotype & 15 & $10.3 \%$ & \\
C/C & & & \\
C/T & 103 & $83.7 \%$ & \\
Serum ALT(U/L) & 20 & $16.3 \%$ & \\
$>40$ & & & \\
$\leq 40$ & 91 & $59.1 \%$ & \\
Viral load HCV RNA(log $10 \mathrm{IU} / \mathrm{mL})$ & & $40.9 \%$ & \\
\hline
\end{tabular}

\section{Virological response}

Among the 154 patients, only 2 of them experienced a viral breakthrough and became HCV-RNA positive again at the sixth and ninth months of therapy, respectively, two individuals were observed HCV viral load decline less than 2 logs at week 12 during therapy, one of the patients' relapse, which were classified as a lack of responders. Rapid viral response at 4 weeks was achieved in 100 patients $(66.7 \%)$, early response at 12 weeks was achieved in 153 patients $(99.4 \%)$. At the end of treatment, $149(96.8 \%)$ patients were SVR and remained HCV-RNA negative during the 6-month follow-up period. Table 2 demonstrated characteristics of 154 children with $\mathrm{CHC}$ associating with SVR. The rate of SVR in male and female was $98.0 \%$ and $94.3 \%$, respectively. $53(93.0 \%)$ of the 57 patients with genotype $1 b, 72(98.6 \%)$ of 73 with genotype $2 a$,
$15(100.0 \%)$ of 15 with undecided type showed SVR. There was no difference in SVR between HCV genotype $2 \mathrm{a}$ and those with HCV genotype $1 \mathrm{~b}(98.6 \%$ vs $93.0 \%, p=0.160)$. The rate of SVR was higher in patients with IL $28 \mathrm{~B}$ genotype $\mathrm{C} / \mathrm{C}$ than genotype C/T (99.0\% vs 80\%, p=0.002). ALT level and AST level was detected in 154 patients, respectively. Among patients with SVR, the ALT level of 88 patients was more than 40U/L and ALT level of 61 patients was less than $40 \mathrm{U} / \mathrm{L}$. AST level of 94 patients was more than $40 \mathrm{U} / \mathrm{L}$ and AST level of 55 patients was less than $40 \mathrm{U} / \mathrm{L}$. HCV RNA viral load was detected in 154 patients. Among those with SVR, 41 patients were more than $6 \times 10^{5} \mathrm{IU} / \mathrm{mL}, 108$ patients were less than $6 \times 10^{5} \mathrm{IU} / \mathrm{mL}$. There was no difference in SVR between the patients with lower baseline viral load ( $\left.<6 \times 10^{5} \mathrm{IU} / \mathrm{mL}\right)$ and higher ones $\left(\geq 6 \times 10^{5} \mathrm{IU} / \mathrm{mL}\right)$ (97.3\% vs $95.3 \%, \mathrm{p}=0.916)$. Also, statistical analysis showed that there were no significant differences in the SVR between ALT $>40 \mathrm{U} / \mathrm{L}$ group and ALT $\leq 40 \mathrm{U} / \mathrm{L}$ group $(96.7 \%$ vs $96.8 \%, \mathrm{p}=1.000)$, AST $>$ 40U/L group and AST $\leq 40 \mathrm{U} / \mathrm{L}$ group $(95.9 \%$ vs $98.2 \%$, $\mathrm{p}=0.654)$.

TABLE 2. Characteristics of 154 children with $\mathrm{CHC}$ associating with SVR

\begin{tabular}{lcllll}
\hline variable & Total & & With SVR & Without & $p$ \\
& & & & SVR & Value \\
\hline Sex & 154 & Male & $99(98.0 \%)$ & $2(2.0 \%)$ & 0.340 \\
& & Female & $50(94.3 \%)$ & $3(5.7 \%)$ & \\
HCV genotype & 145 & 1b & $53(93.0 \%)$ & $4(7.0 \%)$ & 0.160 \\
& & 2a & $72(98.6 \%)$ & $1(1.4 \%)$ & \\
& & Undecided type & $15(100.0 \%)$ & $0(0.0 \%)$ & \\
IL28B genotype & \multirow{2}{*}{123} & C/C & $102(99.0 \%)$ & $1(1.0 \%)$ & 0.002 \\
& & C/T & $16(80 \%)$ & $4(20 \%)$ & \\
Serum ALT(U/L) & \multirow{2}{*}{154} & $>40$ & $88(96.7 \%)$ & $3(3.3 \%)$ & 1.000 \\
& & $\leq 40$ & $61(96.8 \%)$ & $2(3.2 \%)$ & \\
Serum AST(U/L) & \multirow{2}{*}{154} & $>40$ & $94(95.9 \%)$ & $4(4.1 \%)$ & 0.654 \\
& & $\leq 40$ & $55(98.2 \%)$ & $1(1.8 \%)$ & \\
Baseline viral load & \multirow{2}{*}{154} & $\geq 6 \times 10^{5}$ & $41(95.3 \%)$ & $2(4.7 \%)$ & 0.916 \\
(IU/mL) & & $<6 \times 10^{5}$ & $108(97.3 \%)$ & $3(2.7 \%)$ & \\
\hline
\end{tabular}

\section{Adverse events}

Adverse events during recombinant alfa- $2 b$ interferon plus ribavirin therapy were described in the table 3 . And there was moderate fever symptom in $78(50.6 \%)$ patients during the first weeks of treatment. Weakness, myalgia, dizziness were observed in one patient $(0.6 \%)$. 2(1.3\%) patients suffered rhinorrhoea. Gastrointestinal symptoms were observed in 9 patients, among them, $5(3.2 \%)$ were anorexia, $1(0.6 \%)$ was vomiting, $3(1.9 \%)$ were diarrhea. Psychiatric symptoms were found in four patients in the study, $2(1.3 \%)$ of them were insomnia, another $2(1.3 \%)$ were irritability. Febrile convulsions did not occur. In all of 
them the symptoms resolved or were negligible during the second 6 months. Only one patient had anorexia but no severe weight loss. 149 patients in this study suffered hematological changes, $13(8.4 \%)$ of them suffered leucopenia, 107(69.5\%) patients showed neutropenia, $37(24.0 \%)$ patients suffered hemoglobin concentration decrease, $3(1.9 \%)$ patients had platelet count decrease. 7(4.5\%) patients were observed rash. But only $12(7.8 \%)$ patients enrolled in the study developed thyroid autoantibodies. All side effects disappeared after the end of treatment, no patient discontinued treatment due to side effects of alfa- $2 b$ interferon plus ribavirin therapy.

TABLE 3. Frequency of adverse events during recombinant Alfa- $2 b$ interferon plus ribavirin therapy

\begin{tabular}{lll}
\hline Side effect & Number & proportions \\
\hline Influenza-like symptoms & & \\
Fever & 78 & $50.6 \%$ \\
Weak & 1 & $0.6 \%$ \\
Myalgia & 1 & $0.6 \%$ \\
Rhinorrhoea & 2 & $1.3 \%$ \\
Dizziness & 1 & $0.6 \%$ \\
Gastrointestinal symptoms & & \\
Anorexia & 5 & $3.2 \%$ \\
Vomiting & 1 & $0.6 \%$ \\
Diarrhea & 3 & $1.9 \%$ \\
Psychiatric symptoms & & \\
Insomnia & 2 & $1.3 \%$ \\
Irritability & 2 & $1.3 \%$ \\
Hematological changes & & \\
Leucopenia & 13 & $8.4 \%$ \\
Neutropenia & 107 & $69.5 \%$ \\
Hemoglobin decreased & 37 & $24 \%$ \\
Platelet reduction & 3 & $1.9 \%$ \\
Others & & \\
Rash & 7 &
\end{tabular}

\section{Predictive factors for SVR}

Age, viral load, HCV genotype, aspartate aminotransferase and IL28B genotype were selected as possible pretreatment predictive factors of the response to IFN/RBV for further analysis [14-19]. The results of the univariate and multivariate analyses are shown in Table 4. In the univariate and multivariate analysis, no significant association $(\mathrm{p}=0.724, \mathrm{p}=0.619)$ between age and SVR was observed. In addition, HCV genotype $1 b / 2 a(p=0.160, p=0.265)$ and baseline viral load $(p=0.916, p=0.518)$ was not observed for a significant association with SVR.

However, the univariate and multivariate analysis revealed IL28B genotype had a significant association with SVR, and genotype $\mathrm{C} / \mathrm{C}$ was the most potential and critical predictor $(\mathrm{p}=0.002$, $p=0.004)$ for SVR compared with other factors.
TABLE 4. Possible predictors for SVR in children with $\mathrm{CHC}$ by univariate and multivariate logistic regression analysis

\begin{tabular}{|c|c|c|c|c|}
\hline Variable & $\begin{array}{l}\text { SVR } \\
n=149\end{array}$ & $\begin{array}{l}\text { Non-SVR } \\
n=5\end{array}$ & $\begin{array}{l}\text { Univariate } \\
P \text { value }\end{array}$ & $\begin{array}{l}\text { Multivariate } \\
P \text { value }\end{array}$ \\
\hline Age(years) & $2.95 \pm 1.38$ & $2.73 \pm 0.74$ & 0.724 & 0.619 \\
\hline Baseline viral load & & & 0.916 & 0.518 \\
\hline$\geq 6 \times 10^{5} \mathrm{IU} / \mathrm{mL}$ & $41(95.3 \%)$ & $2(4.7 \%)$ & & \\
\hline$<6 \times 10^{5} \mathrm{IU} / \mathrm{mL}$ & $108(97.3 \%)$ & $3(2.7 \%)$ & & \\
\hline HCV genotype & & & 0.160 & 0.265 \\
\hline $1 \mathrm{~b}$ & $53(93.0 \%)$ & $4(7.0 \%)$ & & \\
\hline $2 a$ & $72(98.6 \%)$ & $1(1.4 \%)$ & & \\
\hline Undecided type & $15(100.0 \%)$ & $0(0.0 \%)$ & & \\
\hline IL28B genotype & & & 0.002 & 0.004 \\
\hline $\mathrm{C} / \mathrm{C}$ & $102(99.0 \%)$ & $1(1.0 \%)$ & & \\
\hline $\mathrm{C} / \mathrm{T}$ & $16(80 \%)$ & $4(20 \%)$ & & \\
\hline
\end{tabular}

\section{Discussion}

It is well known that $\mathrm{CHC}$ treatment for the hepatitis C patients in childhood can effectively reduce the risk of progression to cirrhosis in their adulthood. However, there remains a dearth of evidence for such treatments in children. Some studies using interferon-alfa and ribavirin in children aged 3-18 years was observed overall response rates between $41.7 \%$ and $61 \%[1,2,6,20-22]$. Unlike the previous studies, the age of the patients enrolled in our study was 1 to 6 years old, and the SVR rate of the Hepatitis $C$ patients enrolled in the present study was much higher $(96.8 \%)$ than previous ones $(64 \%$ and $50 \%)[6,7]$, although patients enrolled in these studies were treated with similar protocol.

A previous study reported an overall response rate of genotype $2 / 3(84 \%, 21 / 25)$ is much higher than those with genotype $1(36 \%, 33 / 92)$ [23]. Druyts et al. [22] reported SVR in genotypes 1, 2, 3 and 4 were $61 \%$, $87 \%, 89 \%$ and $52 \%$, respectively. Our data demonstrated that there was no correlation between HCV genotype and SVR. The relationship between viral load and SVR is still controversial. Chen et al. [24] reported SVR rate in the patients at the age of 19-76 with non-genotype $1 \mathrm{HCV}$ infection was $91.4 \%$, while SVR rate of HCV genotype 1 was $66.3 \%$, higher viral load appeared to contribute more to the SVR. However, Kim et al. [25] reported HCV genotype 1 and high baseline viral load (HCV RNA >8.0×105 $\mathrm{IU} / \mathrm{mL}$ ) were associated with low SVR rate in the patients at the age of 46 to 66 . In addition, our results indicated that there was no correlation between SVR and the baseline HCV RNA viral load. Our data showed that patients with normal alanine transaminase levels also achieved considerable SVR $(96.8 \%)$ and found that there was no correlation between SVR and ALT level.

Interestingly, two reports found that IL-28B genotype was associated with viral load [14, 26], and we perform further analysis on this matter. The 
rs12979860 polymorphic site distribution difference between the HCV RNA $<6 \times 10^{5}$ group and $\geq 6 \times 10^{5}$ group was compared. $\mathrm{C} / \mathrm{C}$ frequency in those two groups were $86.7 \%$ and $82.8 \%$, respectively, and C/T frequency were $13.3 \%$ and $17.2 \%$, the IL-28B genotype distribution had no association with viral $\operatorname{load}(\mathrm{P}=0.830)$, which was similar with previous results $[27,28]$. The main focus of this study was the potential clinical applicability of IL-28B genotype. Therefore, we further analyzed the utility of IL-28B genotype polymorphism as a predictor of SVR and found that rs12979860 C/C could be utilized to predict a sustained response with $100 \%$ specificity and $98.04 \%$ sensitivity which is higher than previous reports $[12,27]$, we assume the reason for the higher specificity and sensitivity in our study is that the age of patients in our study is younger. C/C was found to be an independently predictive factor associated with SVR in Chinese Children Aged 1 to 6 Years with Chronic Hepatitis C in our study.

The data of this study showed that alfa-interferon- $2 b$ plus ribavirin treatment in children aged 1-6 years with CHC was well tolerated and yielded an encouraging result with $96.8 \%$ SVR, and the most common adverse events consisted of influenza-like symptoms, gastrointestinal complaints and fever. Leucopenia, neutropenia and hemoglobin decrease occurred in approximately $8.4 \%, 69.5 \%$ and $24.0 \%$ of treated children, respectively. Psychiatric symptoms such as insomnia and irritability in most naive patients were mild to moderate in severity. Importantly, severe infections did not occur in any of the children who developed neutropenia in these studies. All side effects disappeared after the end of treatment. Although according to current knowledge, the inflammatory activity in liver tissue is usually mild at the age of 1-6 and may stay at a low level over more than 10 to 15 years, our study showed that better efficacy could be achieved by earlier antiviral treatment for these patients.

In conclusion, compared with $\mathrm{HCV}$ viral genotype, baseline viral load, ALT level and other factors, IL-28B rs12979860 is more suitable for predicting antiviral efficacy in children with $\mathrm{CHC}$. It is inappropriate to take the increase of ALT level as an essential indicator for antiviral treatment in children aged 1-6 years.

\section{Acknowledgments}

This study was supported by Special foundation for innovative science and technology of 302 hospital (YNKT2013002). The funders had no role in study design, data collection and analysis, decision to publish, or preparation of the manuscript.

\section{Author Contributions}

YWZ had full access to all of the data in the study and takes responsibility for the integrity of the data and the accuracy of the data analysis. YWZ and HFZ designed the study. YMS, JFB, YLL, ZQX, DWC, YG, FCW, MZ, YD and SSZ collected the data. YWZ analyzed and interpreted the data. YWZ wrote the first draft. JFB and CL made the statistical analysis. All authors reviewed and approved the final version.

\section{Competing Interests}

The authors have declared that no competing interest exists.

\section{References}

1. Wirth S, Lang T, Gehring S, et al. Recombinant alfa-interferon plus ribavirin therapy in children and adolescents with chronic hepatitis C. Hepatology. 2002; 36: 1280-4.

2. Kjaergard LL, Krogsgaard K, Gluud C. Interferon alfa with or without ribavirin for chronic hepatitis $\mathrm{C}$ : systematic review of randomised trials. BMJ. 2001; 323: 1151-5.

3. Mangi A, Villani MR, Minerva N, et al. Efficacy of $5 \mathrm{MU}$ of interferon in combination with ribavirin for naïve patients with chronic hepatitis $C$ virus: a randomized controlled trial. J Hepatol. 2001; 34: 441-6.

4. Druyts E, Mills EJ, Nachega J, et al. Differences in clinical outcomes among hepatitis $C$ genotype 1-infected patients treated with peginterferon alpha-2a or peginterferon alpha- $2 \mathrm{~b}$ plus ribavirin: a meta-analysis. Clin Exp Gastroenterol. 2012; 5: 11-21.

5. Awad T, Thorlund K, Hauser G, et al. Peginterferon alpha-2a is associated with higher sustained virological response than peginterferon alfa- $2 b$ in chronic hepatitis C: systematic review of randomized trials. Hepatology. 2010; 51: 1176-84.

6. Christensson B, Wiebe $\mathrm{T}, \mathrm{Akesson} \mathrm{A}$, et al. Interferon-alpha and ribavirin treatment of hepatitis $C$ in children with malignancy in remission. Clin Infect Dis. 2000; 30: 585-6.

7. Lackner H, Moser A, Deutsch J, et al. Interferon-alpha and ribavirin in treating children and young adults with chronic hepatitis C after malignancy. Pediatrics. 2000; 106: E53.

8. El-Shabrawi MH, Kamal NM. Burden of pediatric hepatitis C. World J Gastroenterol. 2013; 19: 7880-8.

9. Süoğlu, Elkabes B, Sökücü S, et al. Does interferon and ribavirin combination therapy increase the rate of treatment response in children with hepatitis C. J Pediatr Gastroenterol Nutr. 2002; 34: 199-206.

10. Süoğlu, Elkabes B, Sökücü S, et al. Does interferon and ribavirin combination therapy increase the rate of treatment response in children with hepatitis C. J Pediatr Gastroenterol Nutr. 2002; 34: 199-206.

11. Pineda JA, Caruz A, Rivero A, et al. Prediction of response to pegylated interferon plus ribavirin by IL28B gene variation in patients coinfected with HIV and hepatitis C virus. Clin Infect Dis. 2010; 51: 788-95.

12. McCarthy JJ, Li JH, Thompson A, et al. Replicated association between an IL28B gene variant and a sustained response to pegylated interferon and ribavirin. Gastroenterology. 2010; 138: 2307-14

13. EASL Clinical Practice Guidelines: management of hepatitis $C$ virus infection. J Hepatol. 2014; 60: 392-420.

14. Ge D, Fellay J, Thompson AJ, et al. Genetic variation in IL28B predicts hepatitis C treatment-induced viral clearance. Nature. 2009; 461: 399-401.

15. Thomas DL, Thio CL, Martin MP, et al. Genetic variation in IL28B and spontaneous clearance of hepatitis C virus. Nature. 2009; 461: 798-801.

16. Urban TJ, Thompson AJ, Bradrick SS, et al. IL28B genotype is associated with differential expression of intrahepatic interferon-stimulated genes in patients with chronic hepatitis C. Hepatology. 2010; 52: 1888-96.

17. Tillmann HL, Thompson AJ, Patel K, et al. A polymorphism near IL28B is associated with spontaneous clearance of acute hepatitis $C$ virus and jaundice. Gastroenterology. 2010; 139: 1586-92, 1592.e1.

18. Montes-Cano MA, García-Lozano JR, Abad-Molina C, et al. Interleukin-28B genetic variants and hepatitis virus infection by different viral genotypes. Hepatology. 2010; 52: 33-7.

19. Lin CY, Chen JY, Lin TN, et al. IL28B SNP rs12979860 is a critical predictor for on-treatment and sustained virologic response in patients with hepatitis C virus genotype-1 infection. PLoS One. 2011; 6: e18322.

20. González-Peralta RP, Kelly DA, Haber B, et al. Interferon alfa-2b in combination with ribavirin for the treatment of chronic hepatitis $\mathrm{C}$ in children: efficacy, safety, and pharmacokinetics. Hepatology. 2005; 42: 1010-8.

21. Figlerowicz M, Sluzewski W, Kowala-Piaskowska A, et al. Interferon alpha and ribavirin in the treatment of children with chronic hepatitis C. Eur J Pediatr. 2004; 163: 265-7. 
22. Druyts E, Thorlund $\mathrm{K}, \mathrm{Wu} \mathrm{P}$, et al. Efficacy and safety of pegylated interferon alfa-2a or alfa-2b plus ribavirin for the treatment of chronic hepatitis $C$ in children and adolescents: a systematic review and meta-analysis. Clin Infect Dis. 2013; 56: 961-7.

23. González-Peralta RP, Kelly DA, Haber $\mathrm{B}$, et al. Interferon alfa-2b in combination with ribavirin for the treatment of chronic hepatitis $\mathrm{C}$ in children: efficacy, safety, and pharmacokinetics. Hepatology. 2005; 42: 1010-8.

24. Chen JY, Lin CY, Wang CM, et al. IL28B genetic variations are associated with high sustained virological response (SVR) of interferon- $\alpha$ plus ribavirin therapy in Taiwanese chronic HCV infection. Genes Immun. 2011; 12: 300-9.

25. Kim KH, Jang BK, Chung WJ, et al. Peginterferon alpha and ribavirin combination therapy in patients with hepatitis $C$ virus-related liver cirrhosis. Korean J Hepatol. 2011; 17: 220-5.

26. Rivero-Juárez A, Camacho EA, Perez-Camacho I, et al. Association between the IL28B genotype and hepatitis $C$ viral kinetics in the early days of treatment with pegylated interferon plus ribavirin in $\mathrm{HIV} / \mathrm{HCV}$ co-infected patients with genotype 1 or 4 . J Antimicrob Chemother. 2012; 67: 202-5.

27. Thompson AJ, Muir AJ, Sulkowski MS, et al. Interleukin-28B polymorphism improves viral kinetics and is the strongest pretreatment predictor of sustained virologic response in genotype 1 hepatitis $\mathrm{C}$ virus. Gastroenterology. 2010; 139: 120-9.e18.

28. Chevaliez S, Hézode C, Soulier A, et al. High-dose pegylated interferon-a and ribavirin in nonresponder hepatitis C patients and relationship with IL-28B genotype (SYREN trial). Gastroenterology. 2011; 141: 119-27. 